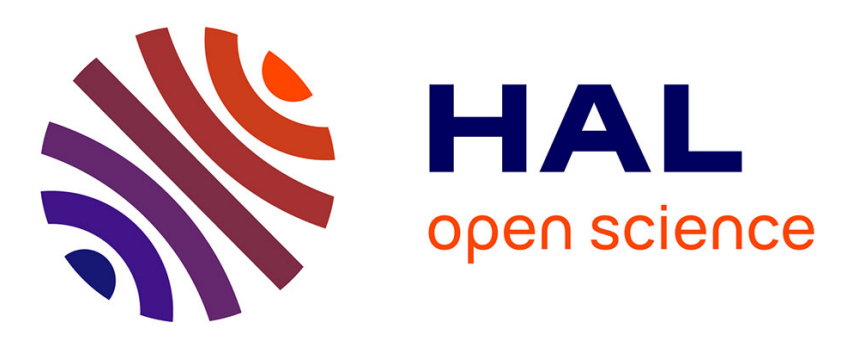

\title{
Acoustic emission monitoring and quantitative evaluation of damage in concrete beams under creep
}

\author{
J. Saliba, A. Loukili, F. Grondin
}

\section{To cite this version:}

J. Saliba, A. Loukili, F. Grondin. Acoustic emission monitoring and quantitative evaluation of damage in concrete beams under creep. Acoustic Emission and Related Non-Destructive Evaluation Techniques in the Fracture Mechanics of Concrete. Fundamentals and Applications, Elsevier, pp.113-136, 2015, 10.1016/B978-1-78242-327-0.00006-4 . hal-02444559

\section{HAL Id: hal-02444559 \\ https://hal.science/hal-02444559}

Submitted on 2 Mar 2020

HAL is a multi-disciplinary open access archive for the deposit and dissemination of scientific research documents, whether they are published or not. The documents may come from teaching and research institutions in France or abroad, or from public or private research centers.
L'archive ouverte pluridisciplinaire HAL, est destinée au dépôt et à la diffusion de documents scientifiques de niveau recherche, publiés ou non, émanant des établissements d'enseignement et de recherche français ou étrangers, des laboratoires publics ou privés. 


\section{Acoustic emission monitoring and quantitative evaluation of damage in concrete beams under creep}

J. Saliba ${ }^{1,2}$, A. Loukili ${ }^{1}$, F. Grondin ${ }^{1}$

${ }^{1}$ UNAM Université, École Centrale de Nantes, Nantes, France; ${ }^{2}$ Université de Bordeaux, Bordeaux, France

\subsection{Introduction}

Concrete structures are susceptible to degradation due to delayed strains that have an impact on their safety margin and lifetime, especially when they are subjected to a high loading level.

Few studies have investigated the effects of creep loading history on failure mechanisms, including its influence on strength, stiffness, and fracture energy. Most of these studies have tried to quantify the effect of creep on the behavior of concrete mainly by measuring the residual strength (Carpinteri, Valente, Zhou, Ferrara, \& Melchiorri, 1997; Cook \& Haque, 1974; Denarié, Cécot, \& Huet, 2006; Liniers, 1987; Omar, Loukili, Pijaudier-cabot, \& Le Pape, 2009; Shah \& Chandra, 1970).

Deformation and fracture of concrete are associated with very complicated progressive failure, and it is usually accepted that the failure process under a sustained load is associated with the development and growth of micro-cracking (Barpi \& Valente, 2005; Bazant \& Li, 1997; Rossi, Godart, Robert, Gervais, \& Bruhat, 1994; Rossi, Tailhan, Le Maou, Gaillet, \& Martin, 2012). Thus, understanding the behavior of concrete requires the detailed assessment of creep and the part of damage. Micro-cracking and damage localization in concrete beams cannot be investigated by the classical mechanical measurements. So, as a part of the investigation, the acoustic emission (AE) technique can be applied.

Nondestructive and instrumental investigation methods such as AE technique have been conducted widely over the last few years. This technique proves to be very effective, especially to check and measure micro-cracking that takes place inside a structure under mechanical loading, and it is particularly recommended for detecting and localizing cracks in concrete (Chen \& Liu, 2004; Granger, Loukili, Pijaudier-Cabot, \& Chanvillard, 2007; Landis \& Shah, 1995; Otsuka \& Date, 2000; Wu, Chen, \& Yao, 2000). 


\subsection{Creep behavior of concrete}

\subsubsection{Creep micro-mechanisms}

Numerous contradictory theories have been put forward over the years to assess the creep behavior of concrete. Since no single mechanism can account for all the observed phenomena, several major real mechanisms can be distinguished, and it is commonly accepted that a combination of these mechanisms act together. Several theories have been suggested: viscous flow (Glanville \& Thomas, 1939), plastic flow (Bernal \& Megaw, 1935), seepage of gel water (Ghosh, 1973), consolidation (Bazant \& Prasannan, 1989), micro-pre-stress of creep sites in cement gel microstructure (Bazant \& Li, 1997), bond breakage in slip and nonlinear deformation, and microcracking (Carrasquillo, Slate, \& Nilson, 1981; Ngab, Slate, \& Nilson, 1981; Rossi et al., 1994). Usually, creep mechanisms are associated with the hydrated cement paste and can be considered as material properties. Micro-cracking is an apparent creep mechanism that can also contribute to the observed deformation and is responsible for the permanent deformation.

Creep has important effects on the stresses and deflections of the concrete structure. For low load levels, it is assumed that linear viscoelasticity takes place, and the instantaneous mechanical behavior of concrete remains elastic. However, for high load levels, micro-cracks, initiated by the local stress, develop and interact with the viscoelasticity (Mazzotti \& Savoia, 2002); deviation of the linearity of the mechanical response may occur and nonlinear creep occurs (Bazant \& Li, 1997; Freudenthalt \& Roll, 1958; Masuero, 1995; Mazzotti \& Savoia, 2002). In fact, micro-cracking may initiate at the moment of load application and begin to grow to form a timedependent crack path (Bazant \& Gettu, 1992; Meyers, Slate, \& Winter, 1969).

Creep deformations under tension present similarities and differences in comparison to creep under compression (Atrushi, 2003; Bissonnette, Pigeon, \& Vaysburd, 2007). Three main mechanisms were recognized for tensile creep (Bissonnette et al., 2007; Garas, 2009): water seepage, viscous shear, and micro-cracking. The study of creep in tension has shown different effects on the behavior of concrete with some contradiction at times. On one hand, creep may relax internal tensile stresses generated by restrained shrinkage and thermal dilation at early ages by increasing the deformation capacity to the rupture and, consequently, reducing the risk of potential cracking in concrete (Altoubat \& Lange, 2001; Bissonnette \& Pigeon, 2000). However, the principal mechanism of tensile creep is due to microcrack development, which could be responsible for the decrease of the residual strength and the modification of concrete properties (Cook \& Haque, 1974; Rossi et al., 1994).

\subsubsection{Limitations of the classical creep and fracture measurements}

The purpose of this section is to investigate the effect of basic creep on the residual capacity of concrete specimens and the fracture energy. 
Table 6.1 Concrete mixture proportions

\begin{tabular}{|l|l|}
\hline Constituent & Dosage $\left(\mathbf{K g} / \mathbf{m}^{\mathbf{3}}\right)$ \\
\hline Gravel: G5/12.5 mm & 936.0 \\
Sand: 0/5 mm & 780.0 \\
Cement: CEMII 42.5 & 350.0 \\
Water & 219.5 \\
Superplasticizer & 1.9 \\
\hline
\end{tabular}

Source: Saliba et al. (2014).

Concrete specimens were mixed with Portland cement CPA-CEMII 42.5, crushed limestone aggregate distributed in fine sand with a maximum size of $5 \mathrm{~mm}$, and crushed gravel of size 5-12.5 mm. A superplasticizer agent has been added for workability. Table 6.1 shows the mix quantities of constituent materials. This mixture is characterized by a water-to-cement $(W / C)$ ratio of 0.56 and a slump of $70 \mathrm{~mm}$. The proportioning of the cement paste, sand, and coarse aggregates were kept constant throughout the program. Concrete beams of size $800 \times 200 \times 100 \mathrm{~mm}^{3}(1 \times h \times b)$ were prepared with an effective span $(S)$ equal to $600 \mathrm{~mm}$ and a notch-to-depth ratio of $0.2\left(a_{0}=\mathrm{h} / 5\right)$.

Concrete beams are submitted to bending creep tests with a high level of sustained load. The bending creep tests are performed on frames placed in a climate-controlled chamber at $50 \% \mathrm{RH}$ and a temperature of $20^{\circ} \mathrm{C}$. The displacement is measured at midspan. Creep develops quickly in the first days of loading (primary creep) and then stabilizes (secondary creep) (Figure 6.1). The larger the applied stress, the more important are all the kinetics and the magnitude of creep displacement.

Then, the beams subjected to creep are removed from the creep frames after four months and are immediately subjected to three-point bending loading up to failure under closed loop crack mouth opening displacement (CMOD) control with a constant loading rate of $0.3 \mu \mathrm{m} / \mathrm{s}$. The fracture test employs a load-controlled universal testing machine as per RILEM-TMC 50 recommendations (RILEM, 1985), based on Hillerborg's method (Hillerborg, 1985).

Figure 6.2 shows the curves of the load-CMOD for the creep beams and comparative beams with the same age and free of loading for four months. The loadCMOD variations are linear up to about $80 \%$ of the ultimate load (phase 1), followed by a nonlinear variation up to the peak load (phase 2). A stable failure is then observed, and the post-peak response seems to be very gradual. The fracture properties (fracture energy, flexural strength...) of concrete are then calculated. The results show a slight increase in energy that may be explained by the strengthening effect due to basic creep in the compression zone (Rao \& Prasad, 2002; Shah \& Chandra, 1970; Zhou, Barn, Lydon, College, \& Iyf, 1995). 


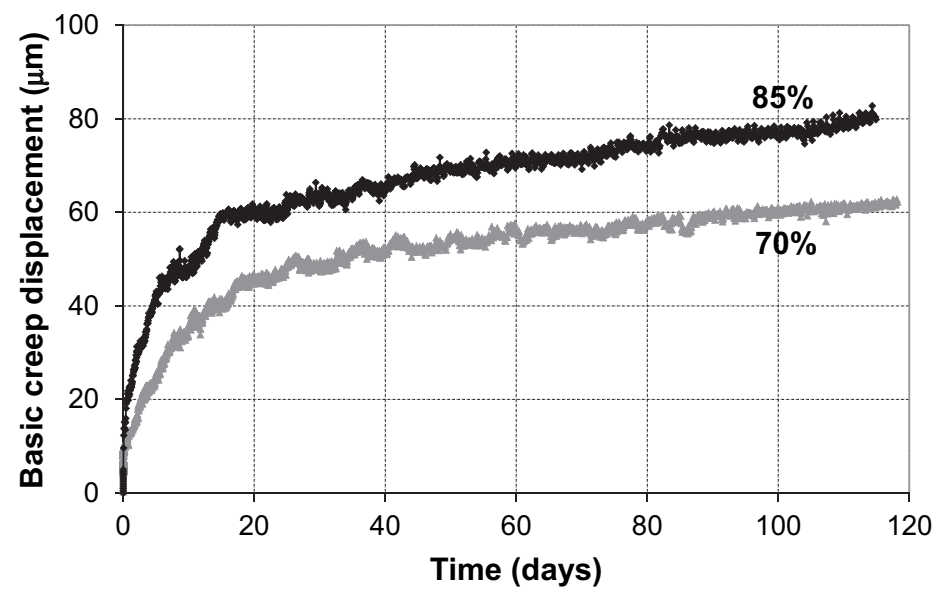

Figure 6.1 Basic creep displacement of notched beams.

Considering the measurement uncertainties, the results do not distinctly show the influence of creep on the fracture behavior due to the small difference between comparative and creep specimens. This small difference was also observed by Hansen (1991), who reported that the fracture energy is independent of the time duration of the sustained load for three-month-old concrete specimens. The Hillerborg method seems to be not fine enough to assess the influence of the creep load on the fracture of concrete.

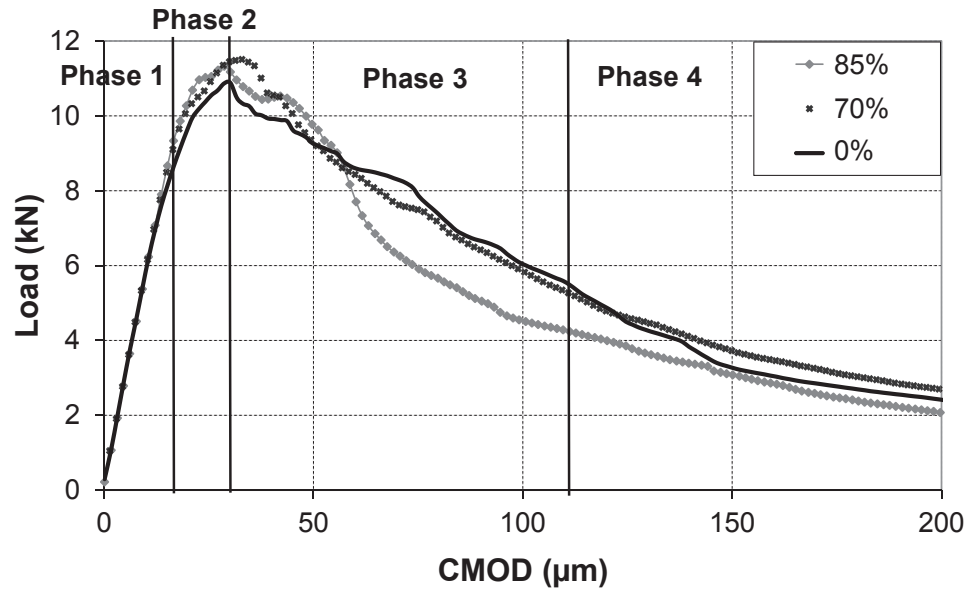

Figure 6.2 Loade CMOD curves for comparative and creep beams. 


\subsection{Application of the acoustic emission (AE) technique to discriminate the creep effect on the cracking behavior}

\subsubsection{Localization of $A E$ events in concrete}

The $\mathrm{AE}$ system is comprised of an eight-channel $\mathrm{AE}$ Win system, a general-purpose interface bus (2 PCI-DISP4), and a PC for data storage analysis. Piezoelectric transducers (resonant frequency of $150 \mathrm{KHz}$ ) were used to convert the mechanical waves to electrical signals. The detected signals were amplified with a $40-\mathrm{dB}$ gain differential amplifier. In order to overcome the background noise, the signal detection threshold was set at a value of about $35 \mathrm{~dB}$ (value adjusted before every test), slightly above the measured background noise. The acquisition system was calibrated before each test using a pencil lead break procedure HSU-NIELSEN (Norme NF EN 1330). The effective velocity and the attenuation of acoustic waves were also calculated. For this analysis, the effective velocity was assumed to be a constant for the analysis of $\mathrm{AE}$ source locations even though there may be some variability depending on the wave propagation path. The effective velocity was assumed to be $3800 \mathrm{~m} / \mathrm{s}$. In order to eliminate mechanical and electromagnetic disturbances, a low-pass filter with a cut-off frequency of $20 \mathrm{KHz}$ and a high-pass filter with a cut-off frequency of $400 \mathrm{KHz}$ were used. Signal descriptors such as rise time, counts, energy, duration, amplitude, average frequency, and counts to peak were captured and calculated by AE Win system. Each waveform was digitized and stored.

During the formation of a crack, energy is emitted as an elastic wave and propagates from the crack location to the $\mathrm{AE}$ transducers at the specimen surface (Figure 6.3). The locations of the AE sources of each event are evaluated based on the arrival times of the first wave at each transducer and their respective velocity in the concrete specimen. On the surface of the beam, four piezoelectric transducers are placed in a rectangular position $\left(120 \times 120 \mathrm{~mm}^{2}\right)$ around the expected location of the fracture process zone (FPZ) to minimize errors in the AE event localization program (Figure 6.3). Once the arrival time is picked, the least-square method is used to estimate the event location. A measurable event has a minimum of three well-defined arrival times.

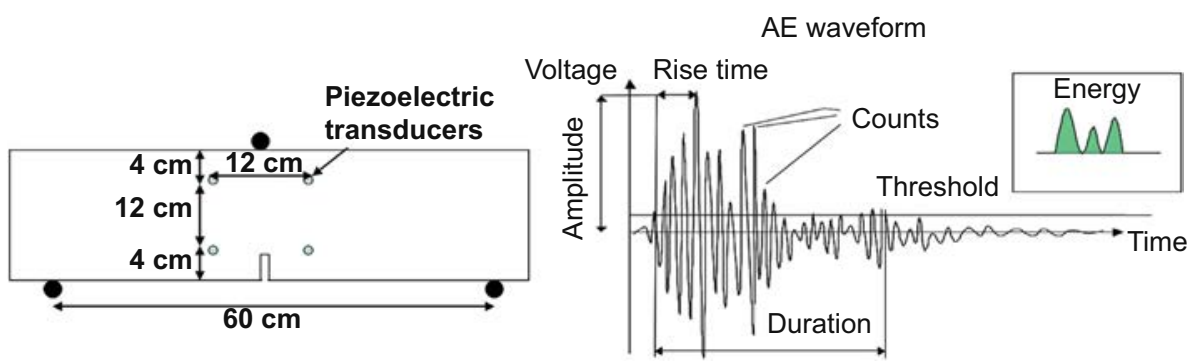

Figure 6.3 Position of the piezoelectric transducers on the beam (left) and an AE waveform (right). 
The location resolution is estimated to be $\pm 5 \mathrm{~mm}$. This accuracy depends on many conditions such as the transducer arrangement, the covering of the herd sphere, the homogeneity of concrete, the coupling of the transducers, and the variation in wave propagation velocity that may arise based on the number of aggregate crossings over the path of wave propagation, and so on. The relevant method is recommended by RILEM TC212-ACD (RILEM, 2010).

The locations of the $\mathrm{AE}$ sources are analyzed in the four stages of the fracture test (elastic stage, precritical crack growth, critical crack growth, crack bridging) (Van Mier, 2008). The cumulated locations of acoustic events are shown in Figure 6.4(a)-(d) for comparative and creep specimens. Each plotted point indicates a detected AE source. The damage accumulation is observed over a window as a function of the position $x$ and $y$ centered at the notch, with a width of $300 \mathrm{~mm}$ and covering the beam depth.

The AE events are evenly distributed throughout the zone of maximum tensile stress in the specimen, and the AE sources are localized in a band describing the way of the propagation of the crack. The comparison between comparative and creep specimens shows many differences. More events are recorded with creep specimens. The AE activity, proportional to the density of micro-cracking, shows a more intense localization of micro-cracks and, thus, a clearer active damage zone.

In the first stage, the $\mathrm{AE}$ activity is more important for comparative specimen indicating an early crack initiation in the pre-peak region (Figure 6.4(a)). This behavior is correlated to the shape of the load-CMOD curve. In fact, the linear elastic phase of creep beams is more important than comparative beams where the nonlinear behavior begins at a low loading rate. A recent study on the size effect (Alam, Loukili, \& Grondin, 2012) showed that a crack initiates at 50\% in the pre-peak regime for small beams and then continues to grow gradually, while a crack initiates just before the peak load for larger beams. The same behavior is observed here with creep specimens, where the crack length is obviously delayed (Figure 6.4(b)). Thus, the behavior of creep specimens seems to be close to that of specimen of larger size that have more brittle behavior.

\subsubsection{Correlation of load-CMOD curve and AE parameters}

$\mathrm{AE}$ hits provide an indication of the number of burst emissions or events and other wave characteristics, such as the amplitude and the energy (Figures 6.5 and 6.6). During the initial loading stage, corresponding essentially to the linear portion of the load-CMOD curve (pre-peak), the AE activity is weak, and few events are located. Micro-cracks nucleate in a somewhat random pattern in the zone of the maximum tensile stress. In addition, the amplitude and the energy of the waves released at this stage are weak, and thus, micro-cracks occurring early in the loading cycle could be attributed to primarily matrix-aggregate interface cracks.

The second set of event locations corresponds to the pre-peak nonlinear region as the load reaches about $80 \%$ of the maximal strength. The AE activity becomes more intense, indicating the formation of micro-crack bands. In this stage, damage starts to localize around the notch tip forming the FPZ (Landis \& Shah, 1995; Li \& Shah, 

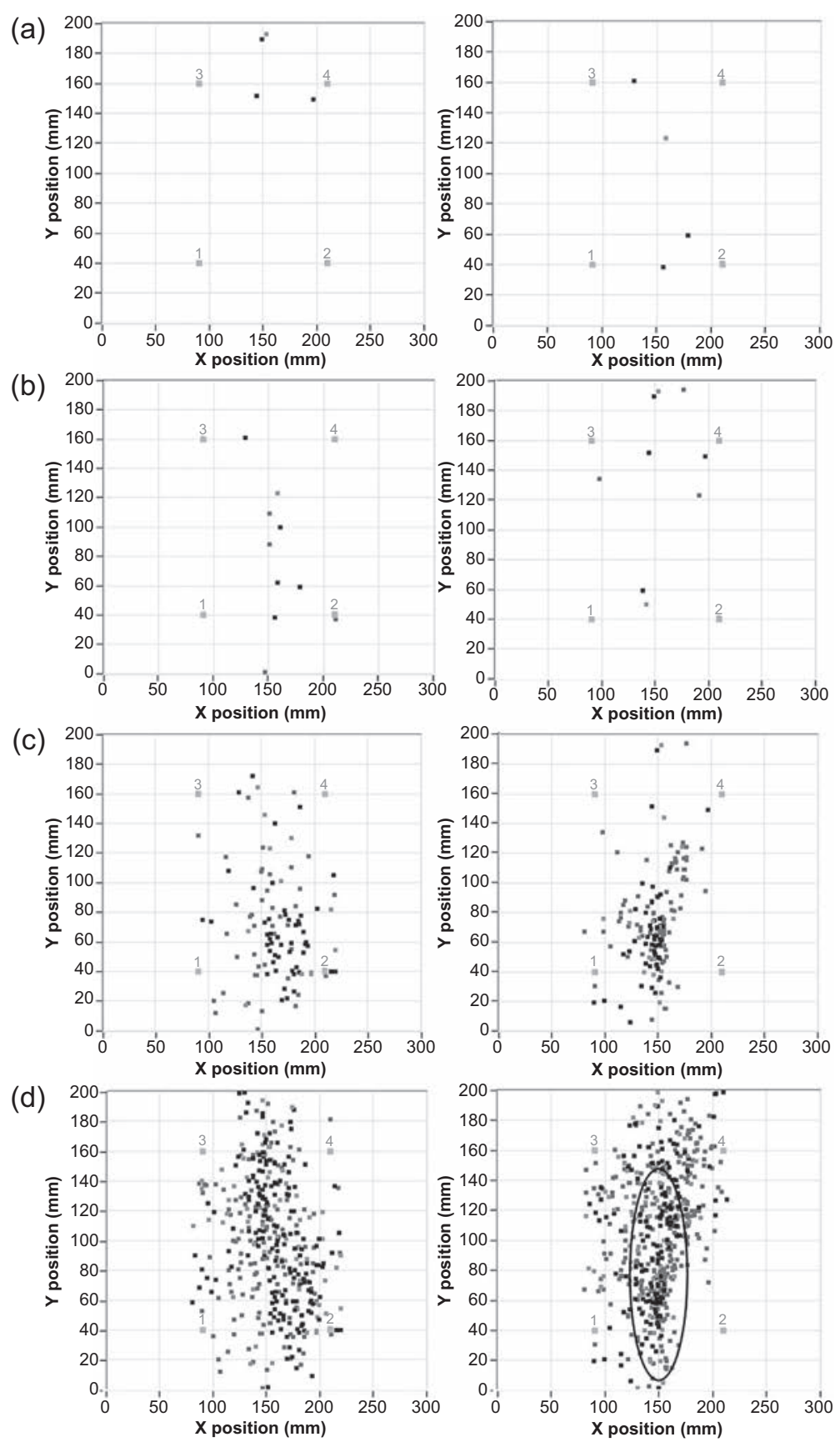

Figure 6.4 Maps of the AE sources located at four stages of the loading for aging specimen (left) and creep specimen (right): (a) 0 e $80 \%$ of the peak load, (b) 80e $100 \%$ of the peak load, (c) $100 \mathrm{e} 40 \%$ of the peak load in the post-peak region, (d) total localization map. 
(a)

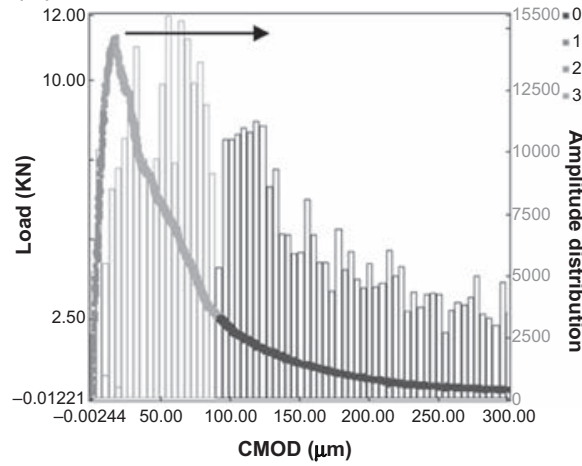

(b)

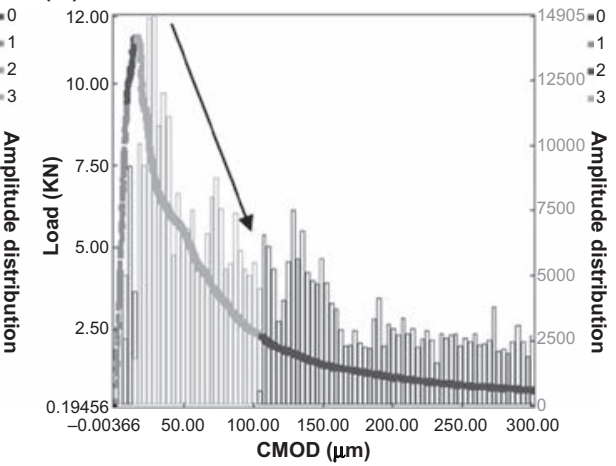

Figure 6.5 Correlation of loade CMOD curve with AE amplitude distribution for aging (a) and creep beams (b) during the four phases.

Source: Saliba et al. (2012).

(a)

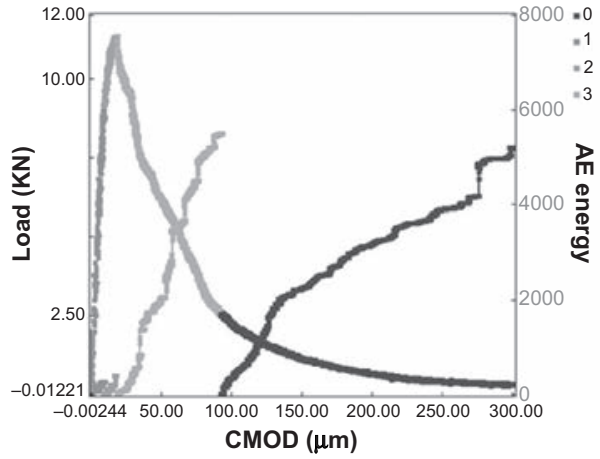

(b)

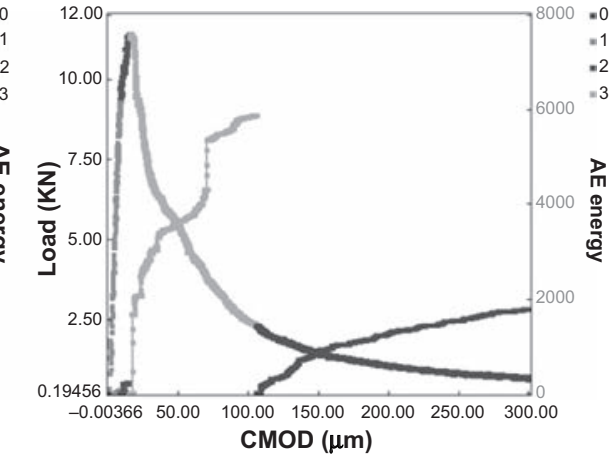

Figure 6.6 Correlation of loade CMOD curve with AE energy rate for aging (a) and creep beams (b) during the four phases.

Source: Saliba et al. (2012).

1994). As the load approaches the peak, a higher energy is released, indicating that there is matrix cracking (Landis, 1999).

After the peak load, the AE activity increases rapidly in a third phase. This increase is associated with the high surface corresponding to cracks that develop when the external load exceeds the ultimate strength (Kim \& Weiss, 2003). In fact, in the beginning, micro-cracks start to develop at the surface of the concrete, and at this point, microcracks coalesce into an area around the location of the critical macro-cracking until visible unstable cracking appears. As can be seen in Figure 6.4, the locations of the AE sources increase with time, and the area becomes wider and spreads away from the notch tip. At this stage, concrete damage increases gradually with a constant AE rate. 
The amplitude distribution versus CMOD curve shows that there exists a plateau in comparative specimens and that the number of AEs remains approximately constant during the third phase, with no obvious occurrence of $\mathrm{AE}$ peak distribution (Figure 6.5). Whereas, the amplitude distribution for creep specimens peaks in the region of $80-90 \%$ of the maximum load in the descending branch of load-CMOD, and then it decreases brutally, indicating a more brittle behavior for concrete beam subjected to creep. Thus, creep influences the AE characteristics and changes the distribution of hits occurring in the descending branch of the load-CMOD curves, which shift to the latter with comparative specimens.

Energy rate jumps are observable at certain point (Figure 6.6). These discrete jumps in the energy release rate may be explained by an aggregate acting to arrest cracks before they propagate across the specimen, requiring a greater driving force to propagate across the specimen (Kim \& Weiss, 2003).

The distinguishing characteristic that separates the initial post-peak and terminal post-peak region is the slope of the cumulative event count plot. In the terminal post-peak region, the AE activity rate decreases. This is probably due to the existence of the fracture surface inside the FPZ and the decrease of stress (Hadjab, Thimus, \& Chabaat, 2007). AE events are generated as a consequence of different toughening mechanisms through the crack faces on micro- and meso-levels, such as friction and bridging (Shah \& Ouyang, 1994). The rate of the absolute AE energy decreases in the fourth phase (Figure 6.6). However, some AE hits present high amplitude and energy toward the end, indicating different toughening mechanisms.

\subsubsection{Calculation of the FPZ width by an AE-based method}

The FPZ surrounding the crack tip is one of the principal mechanisms in the fracture of quasi-brittle materials, and presently is considered the hottest topic in the field of concrete fracture mechanics. This zone is characterized by complex micro-structural features in concrete in the vicinity of a macro-crack front, such as frictional interlock between tortuous cracked surfaces and discontinuous fractures of unbroken aggregate bridging and other inelastic, irreversible material changes that dissipate energy (Shah \& Choi, 1999). This energy absorption during crack growth manifests itself in the nonlinear stress-strain behavior and the strain softening post-peak behavior. Landis and Baillon (2002) and Wu et al. (2000) suggest that the energy dissipated by fracture is proportional to the energy measured by $\mathrm{AE}$ technique, whereas the energy dissipated by toughening mechanisms do not produce a proportional response.

The size of the FPZ can be significant and depends on many parameters upon the material's microstructure: grain size, rate of loading, dimensions of the specimen (Otsuka \& Date, 2000), and other parameters such as notch depths (Zhang \& Wu, 1999).

The approach used to measure the crack band width consists of dividing the specimen into an array of rectangular elements and counting the AE events located within each element (Haidar, Pijaudier-Cabot, Dubé, \& Loukili, 2005). The fineness of the grid $\left(2 \times 2 \mathrm{~cm}^{2}\right)$ is chosen to be large enough to give a sufficient number of events per element and not too small compared to the accuracy of the AE localization method. 

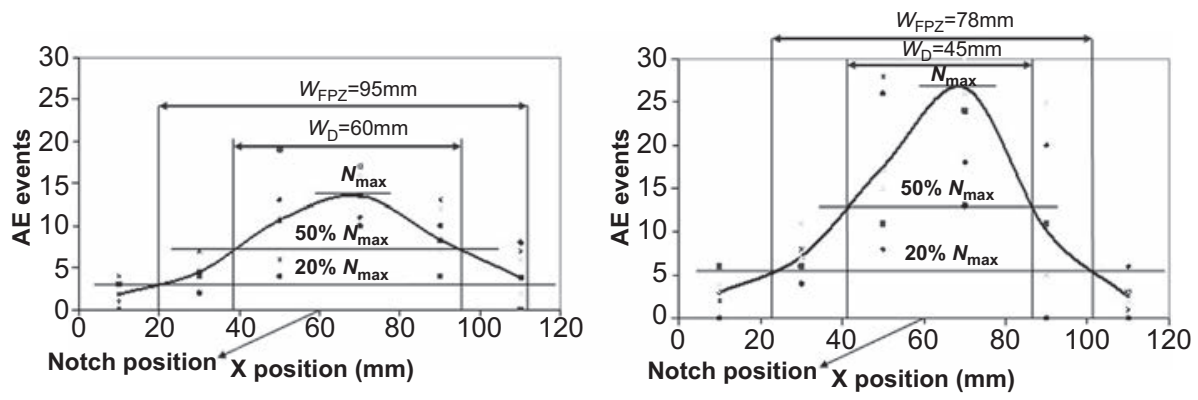

Figure 6.7 Evolution of cumulative events per grid: comparative specimen (left) and creep specimen (right).

Source: Saliba et al. (2012).

The cumulative number of events over the entire record during the experiment is plotted as a function of its horizontal position $x$ for various vertical positions $y$ over the depth of the specimen at the final load step. The average curve is then presented in a continued line. The horizontal straight line, which intersects the vertical axis at the value of $20 \%$ of the maximum number of events on the average curve $\left(N_{\max }\right)$, is plotted in the same graph (Figure 6.7). The crack band width was defined as the length of the segment of this horizontal straight line that intersects the average distribution of AE events. The FPZ could be divided into two areas (Hadjab et al., 2007):

1. The first area corresponds to a zone of confidence of events in which the number of AE events have higher values related to the damage of the material in front of the macro-crack.

2. The second area represents the lower percentage of $\mathrm{AE}$ events corresponding to lower damage.

The width of the damage zone is determined by drawing a line at $50 \%$ of $N_{\max }$ (Rossi, Robert, Gervais, \& Bruhat, 1990). The value of the FPZ is about 95 and $78 \mathrm{~mm}$ and the width of the damage zone is about 60 and $45 \mathrm{~mm}$ for comparative and creep specimens, respectively. This difference can also be seen in Figure 6.4 where $\mathrm{AE}$ events are located in a smaller region in creep specimens. Based on these figures, the propagation of the FPZ can also be measured forward according to the loading stages (Otsuka \& Date, 2000). This decrease of the FPZ is consistent with the results obtained by Omar (Omar et al., 2009) that show the same decrease in the size of the FPZ obtained from the size effect law and the characteristic length fitted before and after creep and, again, a more brittle behavior in the specimen.

There are several reasons for this discrepancy: on one hand, the change in the microstructure of the material under creep due to the creation of micro-cracking and defects (Rossi et al., 1994), and on the other hand, the consolidation of the cement paste in the compression zone during the creep test. The first phenomenon is more significant in the tensile zone of the beam where tensile creep is largely a result of time-dependent micro-cracking (Cook, 1972). As tests have been made without mass exchange, those micro-cracks may be due to the adsorption of internal water into the 
tips of preexisting or load-induced cracks, and thus more intense localization of microcracks in concrete creep beams.

But what is the reason for this brittleness after creep? And how do micro-cracks develop in the microstructure during creep?

\subsection{Assessment of damage mechanisms occurring under creep}

\subsubsection{Localization of $A E$ events in concrete during creep}

In order to have more information on the AE activity, eight piezoelectric transducers are used to convert the mechanical waves to electrical signals and are placed in a 3-D parallelepiped position on both sides of the specimen around the expected location of the FPZ. Figure 6.8 shows the localization map of the AE sources in a concrete beam during a basic creep period and followed by a desiccation creep period. The cumulated locations of acoustic events detected throughout the test are observed over a window as a function of the position $x$ and $y$, centered at the notch with a width of $200 \mathrm{~mm}$ and covering the beam depth, and as a function of the position $y$ and $z$.

During basic creep, events are arbitrarily distributed and diffused along the length $(x, y)$ and the depth $(y, z)$ of the specimen (Figure 6.8(a)). During desiccation, the number of $\mathrm{AE}$ events increases with a higher rate and more energetic events, especially at the surfaces (Figure 6.8(b)). Those events are highly dependent on desiccation. In fact, the nonuniform desiccation (humidity gradient) induces a nonuniform shrinkage in the specimen and, thus, presents structural consequences (Bazant \& Gettu, 1992; Bisschop \& Van Mier, 2002). Then, events begin to localize at the front of the notch in the zone of the maximum tensile stress. As the average stress along the ligament surface is lower than the stress in front of the crack, micro-cracks relax the stress in front of the FPZ by the creation of new crack surfaces. Then, events follow a conical progress before the total failure where there is an emission of high amplitude and energetic signals (Figure 6.8(c)). Those results allow for the understanding of the influence of creep on the brittleness of concrete observed during the failure of beams subjected to creep (Saliba, Loukili, Grondin, \& Regoin, 2012). Note here that the relative kinetics of acoustic waves does not present an important variation during the test.

\subsubsection{Correlation between creep displacement and $A E$ parameters}

The correlation between creep displacement and the characteristics of AE signals collected during creep is shown in Figure 6.9. The AE activity is important during primary creep with the emission of high amplitude signals and then decreases and stabilizes during secondary creep. At this moment, when the beam is subjected to desiccation, the number of AE hits increases quickly with the emission of high amplitude signals, then it decreases progressively in correlation with shrinkage. The 


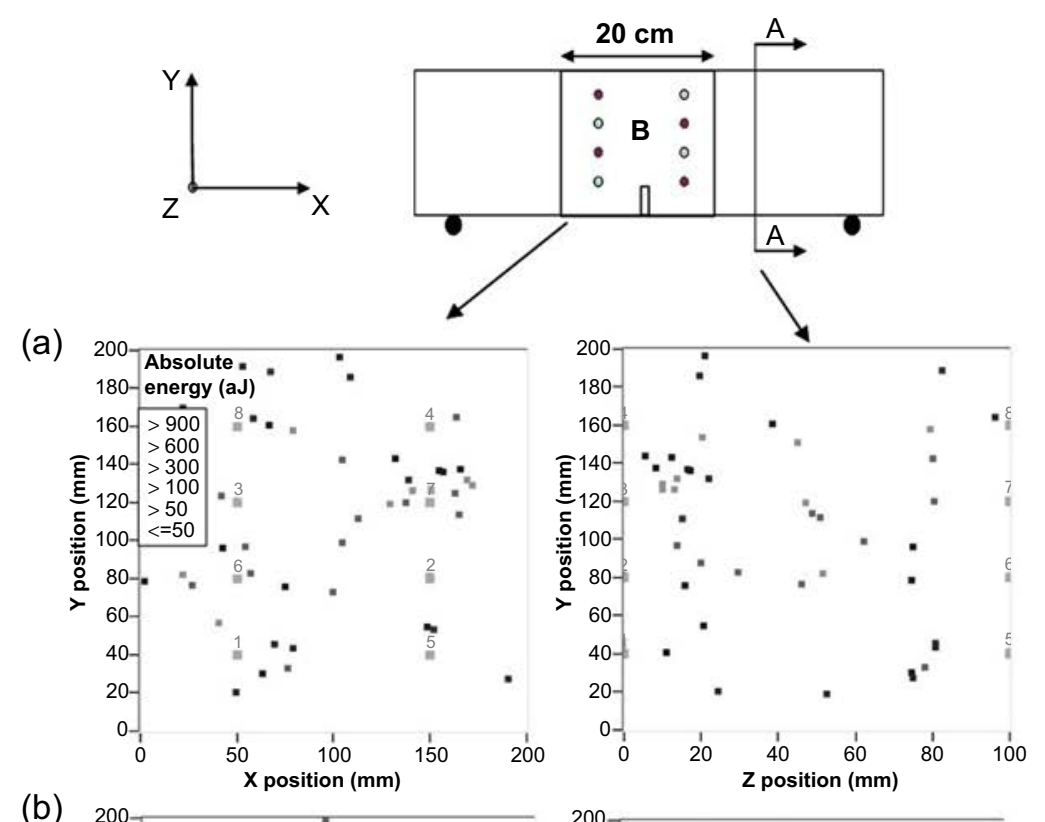

(b)

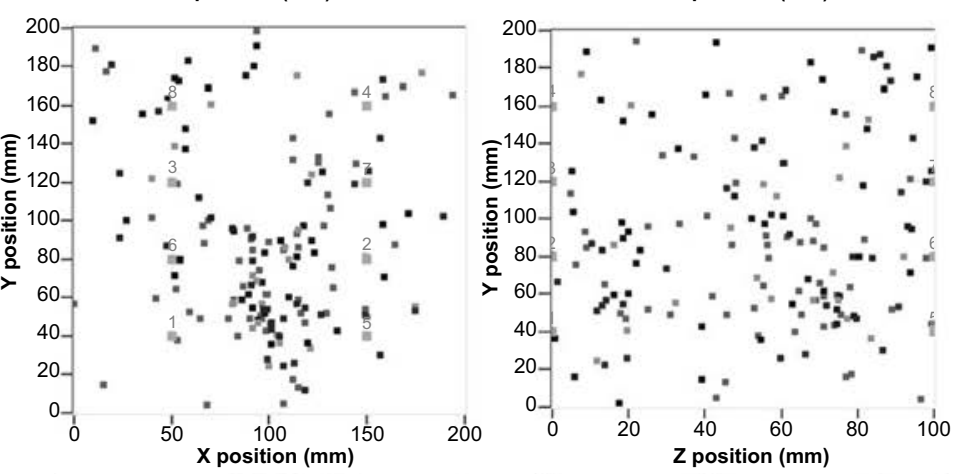

(c)

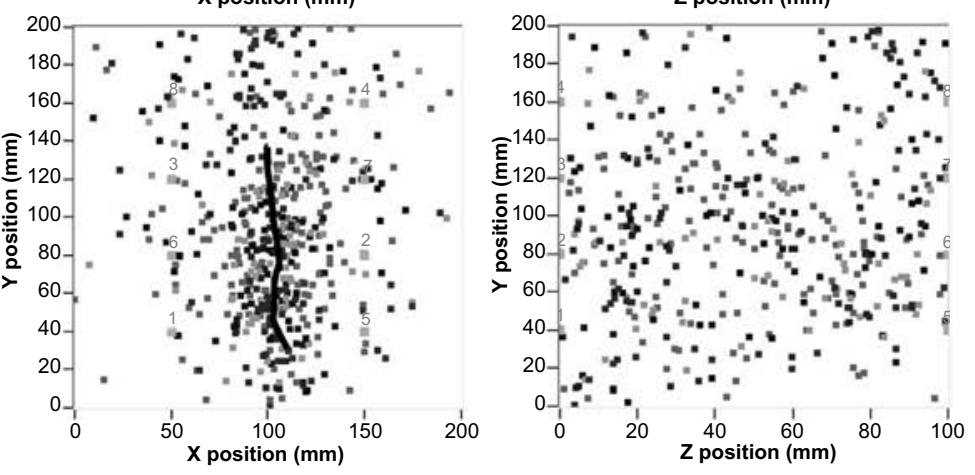

Figure 6.8 Damage localization during (a) basic creep, (b) desiccation creep, and (c) at the rupture in the planes A and B.

Source: Saliba et al. (2014). 

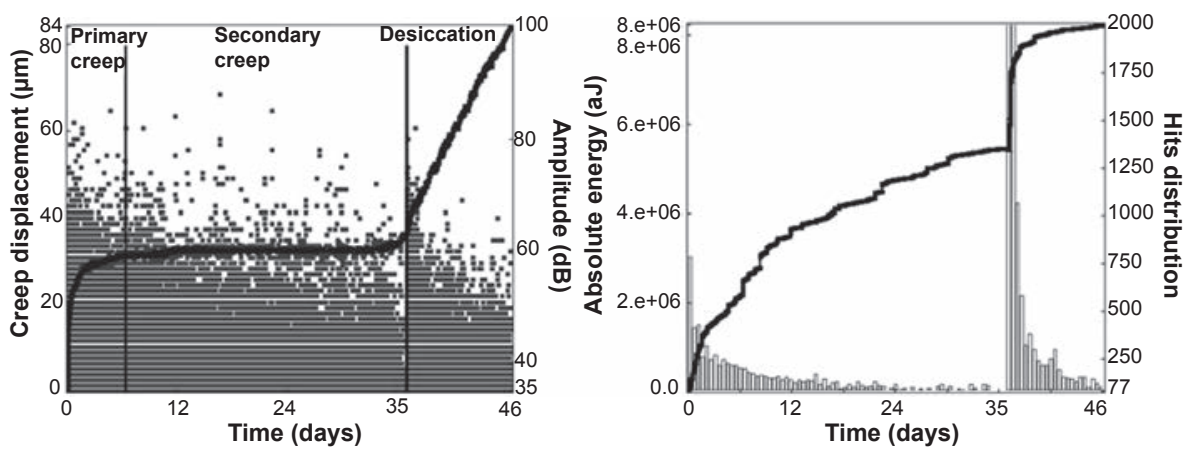

Figure 6.9 Correlation between creep displacement and AE hits amplitude (left); correlation between the cumulated $\mathrm{AE}$ energy and the distribution of the $\mathrm{AE}$ hits during creep test (right). Source: Saliba et al. (2014).

cumulated AE energy follows the same evolution and gives information on the crack initiation that progresses until the failure. Thus, it could be related to the fracture energy measured on a global scale. This finding strengthens the assumption that the acoustic events recorded during creep are related to the creation of micro-cracks or, in other terms, the damage occurring inside the material under creep.

\subsubsection{Multivariable data clustering of AE signals}

The quantitative understanding of the physical processes and the micro-structural phenomena that control the fracture behavior on the macroscopic scale is poor. During the last few years, quantitative evaluation of fracture processes in concrete consisted of evaluating the different modes of failure and stress fields based on moment tensors (Finck, Yamanouchi, Reinhardt, \& Grosse, 2003; Grosse \& Finck, 2006; Ohtsu, Kaminaga, \& Munwam, 1999) and some AE indices as the average frequency and the RA value, defined as the rise time over the amplitude (Aggelis, 2011). It then appears necessary to take the analysis further to obtain information about the physical mechanisms, the origin of the AE signatures. For this, a multivariable analysis of the recorded acoustic signals is proposed to discriminate the damage mechanisms in the material according to the typical AE signals and their apparition chronology.

For the classification process of the monitored $\mathrm{AE}$ data under creep, the unsupervised method $\mathrm{K}$-means associated with a principal component analysis (PCA) and the dendrogram are proposed (Kostopoulos, Loutas, Kontsos, Sotiriadis, \& Pappas, 2003). The K-means method allows obtaining an unsupervised classification in $n$ class representative of the $n$ damage mechanisms in the case of multidimensional data. The PCA method is achieved in order to improve the visualization of the classification results by reducing the dimension of the data (Oja, 1989). In the unsupervised method, each signal can be associated with a pattern composed of multiple relevant features extracted from the random $\mathrm{AE}$ waveforms (amplitude, energy, rising time, average 


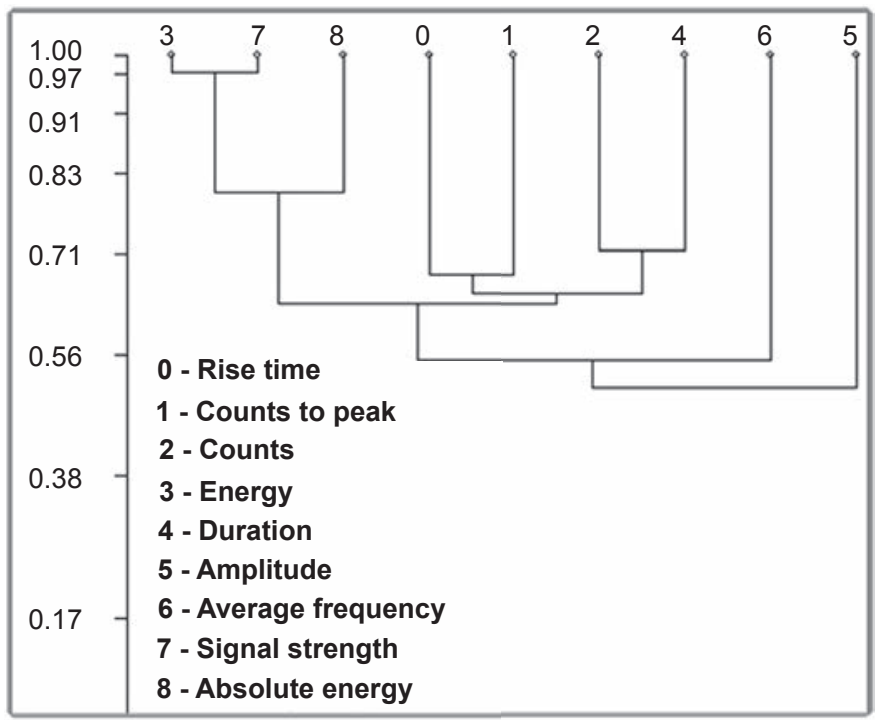

Figure 6.10 Correlation dendrogram of AE features.

Source: Saliba et al. (2014).

frequency, etc.). Those parameters can be correlated and, consequently, redundant. It is then necessary to choose those descriptors wisely. The parameters were classified hierarchically with the dendrogram (Figure 6.10), which exhibits the correlation level among the AE features. The descriptors used are the energy, the absolute energy, the amplitude, the rise time, the counts, the counts to peak, the average frequency, and the duration of the signals. The descriptors are normalized in the interval of $[-1 ; 1]$ to impose an equivalent weight factor to each $\mathrm{AE}$ component.

The results of the K-means method for a correlation level set to 0.9 are presented in Figure 6.11 in 2-D as a function of the first and second principal components that represent the most important variance of $\mathrm{AE}$ parameters. Two clusters are distinguished for basic creep and three for desiccation creep. The clusters are well separated and discriminated.

In the case of basic creep, the first cluster corresponds to signals of weak energy, whereas the second cluster corresponds to signals of higher energy (Figure 6.12). For desiccation creep, the same behavior is observed for clusters 1 and 2, and the additional cluster 3 is characterized by signals of very weak energy. The chronological apparition of these clusters shows that the first is the most distinguished damage mechanism during basic creep and involves much more numerous AE hits than the second class (Figure 6.13). During desiccation creep, the same trend is observed for the first two clusters, and the AE hits distribution of the third cluster appears to be the most important, mainly at the beginning of desiccation, and it decreases with time. In addition, the number of $\mathrm{AE}$ hits for clusters 1 and 2 increases in desiccation in comparison with basic creep. 

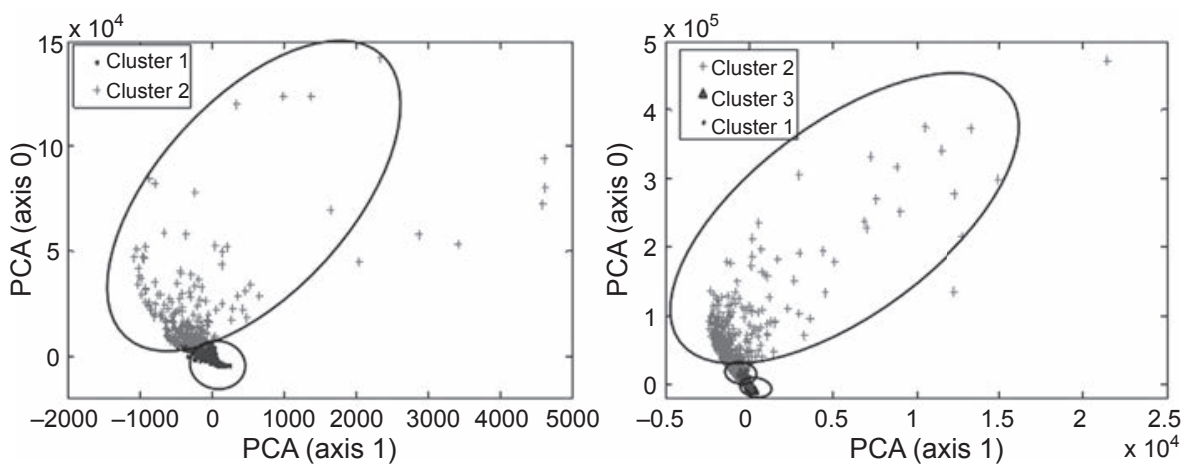

Figure 6.11 Visualization of the PAC clusters for basic (left) and desiccation creep (right). Source: Saliba et al. (2014).
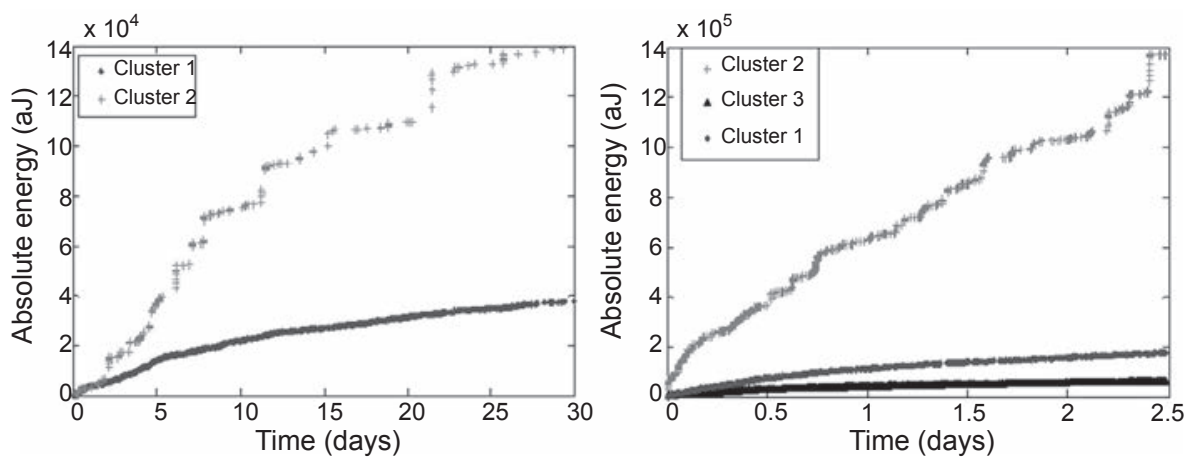

Figure 6.12 Cumulated energy for each cluster during basic (left) and desiccation creep (right). Source: Saliba et al. (2014).

The number of hits by amplitude recorded is averaged to create an experimental distribution of the AE hits amplitude for each cluster and is fitted with a statistical Laplacee Gauss model:

$$
f_{(x)}=\frac{1}{\mathrm{~s} \sqrt{2 \pi}} e^{-\frac{1}{2}\left(\frac{x-m}{\mathrm{~s}}\right)^{2}}
$$

where $f_{(x)}$ represents the statistical variation of the population, $\mathbf{S}$ the population standard deviation, which corresponds to the full width at half maximum, $x$ the studied parameter, and $m$ the population mean (mode). 

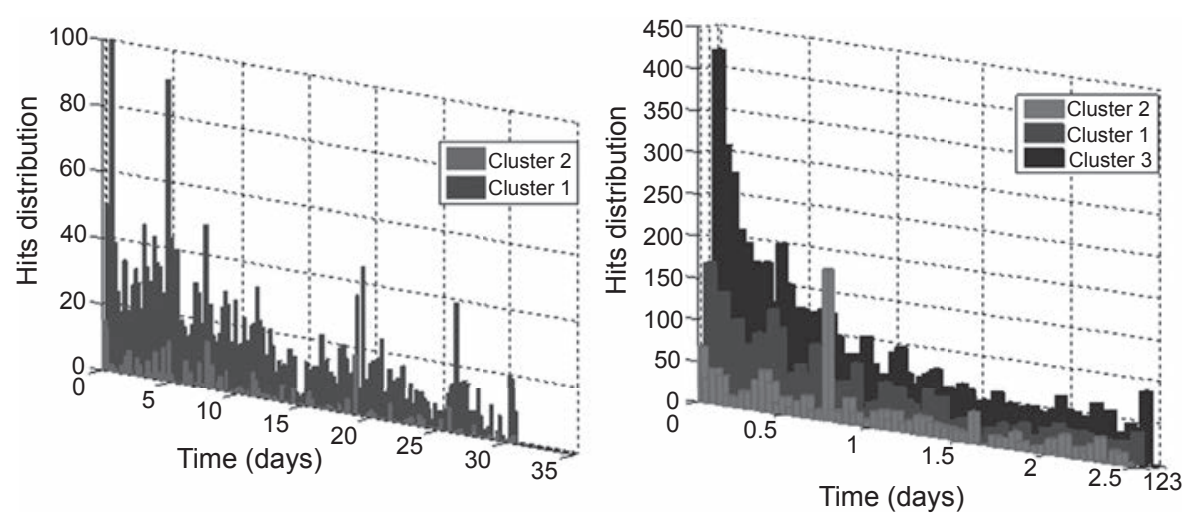

Figure 6.13 Apparition Chronology of the clusters during basic (left) and desiccation creep (right).

Source: Saliba et al. (2014).

Figure 6.14 shows the experimental distribution and the corresponding statistical law of the AE hits amplitude for each class. The mode of the AE hits amplitude distribution for the first cluster is $42 \mathrm{~dB}$, and the range is between 36 and $47 \mathrm{~dB}$. It can be associated with micro-cracking at the matrixeaggregate interface (Rossi, Robert, Gervais, \& Bruhat, 1989). For the second class, the mode is $50 \mathrm{~dB}$, the range is
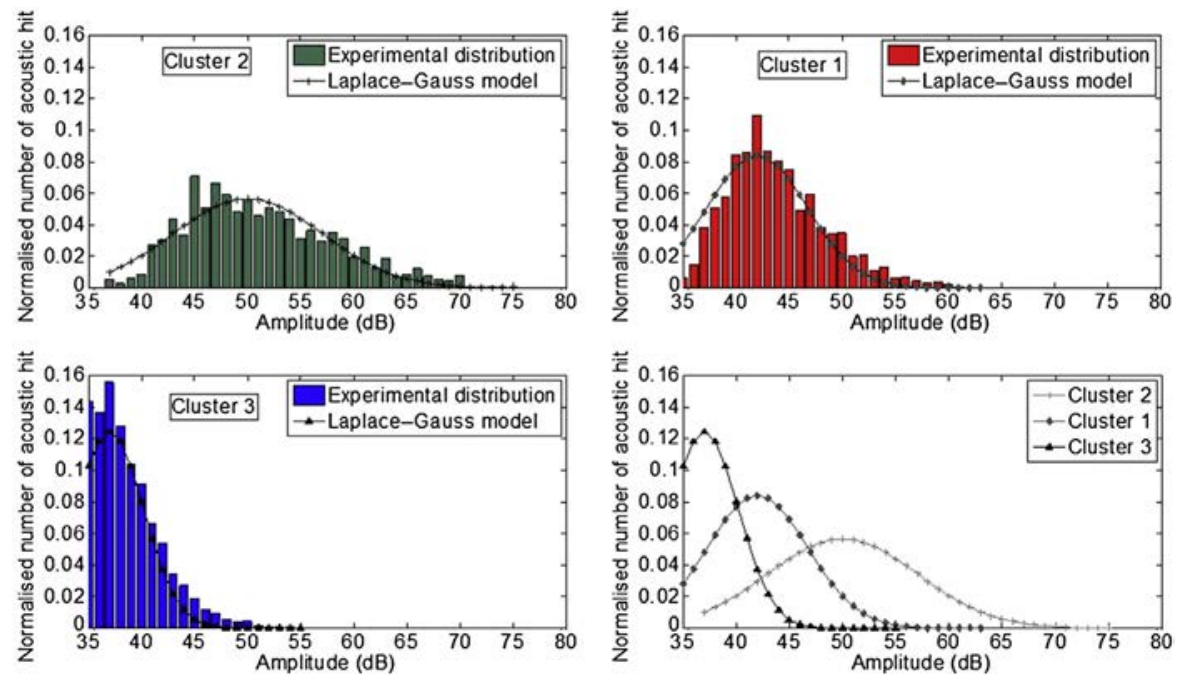

Figure 6.14 Experimental and statistical AE hits amplitude distributions for each cluster.

Source: Saliba et al. (2014). 
between 42 and $59 \mathrm{~dB}$, and it can be associated with micro-cracking in the matrix (Rossi et al., 1989). For the third cluster, the mode is $37 \mathrm{~dB}$ and the range is between 35 and $41 \mathrm{~dB}$. Based on the variation of the AE parameters, this cluster could correspond to signals due to drying as liquid transfer in concrete (Chotard, Quet, Ersen, \& Smith, 2006; Chotard, Smith, \& Quet, 2007) and cavitation (Lura, Couch, Jensen, \& Weiss, 2009). Note that the differences between ranges of amplitude of classes obtained here could be different for other specimen geometries and recording system parameters. The ranges have to be considered as relative differences.

\subsubsection{Effects of desiccation creep on AE activity}

The use of the AE method shows that it is possible to identify the most critical damage mechanisms leading to the final failure of concrete. In order to study the damage evolution during the three creep phases at the micro-structural level and, more particularly, tertiary creep, the AE technique can also be used during desiccation creep tests. The possibility of assessing the time to failure of the tested beams from $\mathrm{AE}$ is shown. Figure 6.15 presents the evolution of the AE activity during the desiccation creep test at $70 \%$. The AE activity is followed by the three distinct phases of creep corresponding to the evolution of creep displacement into three regimes: primary creep, secondary creep, and tertiary creep. Those phases generate different signals covering different ranges of amplitude and corresponding to different damage mechanisms.

The AE activity is important during primary creep with $\mathrm{AE}$ hits of high amplitude and an important emission of AE energy (Figure 6.15). The rate decreases in correlation with the rate of creep displacement. During this phase, the events are arbitrarily distributed, especially in the tension zone (Figure 6.16(a)), and may correspond to the initiation and the development of micro-cracks inside the material as other physical
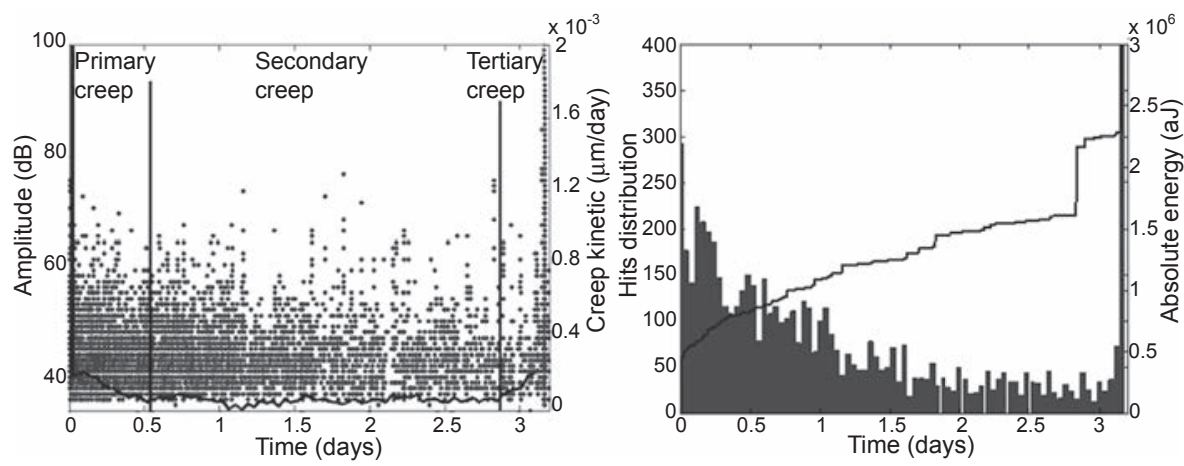

Figure 6.15 Correlation between the creep kinetic and the AE hits amplitude (left); correlation between the cumulated AE energy and the distribution of the AE hits (right).

Source: Saliba et al. (2014). 

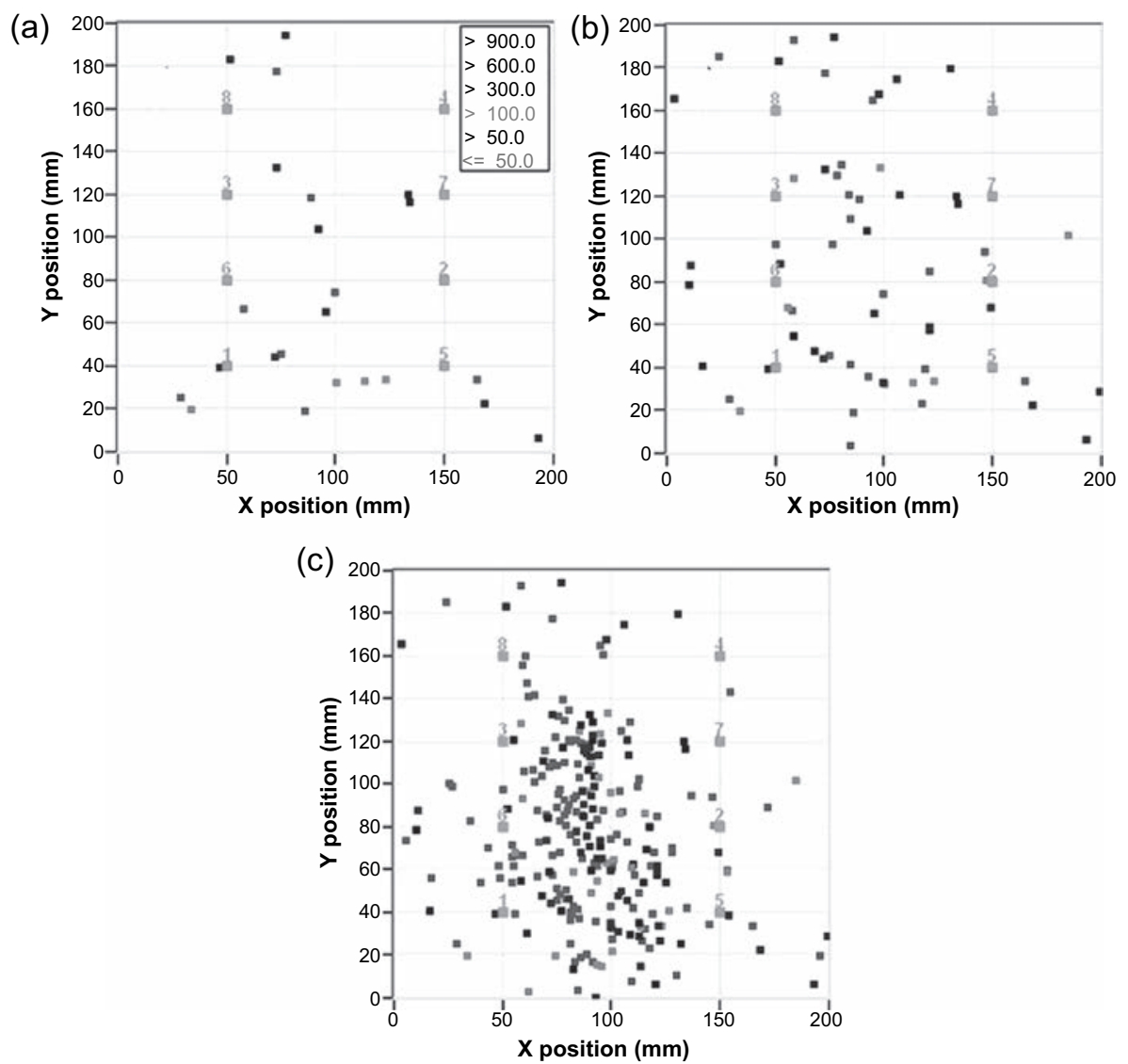

Figure 6.16 Localization of AE events during the (a) primary, (b) secondary, and (c) tertiary desiccation creep test loaded at $70 \%$.

Source: Saliba et al. (2014).

mechanisms responsible for creep as water and stress redistribution in the beams and, consequently, micro-cracking.

During secondary creep, the rate of the AE activity is quasi-constant with a stable evolution of AE energy (Figure 6.15). The number of events continues to increase with different energetic value near the notch (Figure 6.16(b)). This phase corresponds to the apparition of a new damage mechanism due to the extension and the propagation of micro-cracking. Stresses are also generated by the deformation incompatibility between the aggregate and the cement paste (Idiart, López, \& Carol, 2011; Saliba, Loukili, Grondin, \& Regoin, 2014). This could be seen on the localization map, which presents events of different energy corresponding to different damage mechanisms as micro-cracks at the interface between the matrix and aggregate and into the matrix (Saliba, Grondin, Matallah, Loukili, \& Boussa, 2012). 
During the last phase, creep evolves toward the tertiary creep regime where the strain rate accelerates up to failure. The AE activity increases quickly with the emission of very energetic signals. This phase corresponds to the coalescence and the fast propagation of micro-cracks, generating a localized crack and leading to the failure of the specimen in the third day. The amplitude of the AE signals in this phase covers different ranges and sometimes reaches $100 \mathrm{~dB}$ at the failure, where the events begin to concentrate in the cracking zone to finally create a macroscopic crack (Figure 6.16(c)).

The stress concentration and redistribution are responsible for the failure and depend highly on the rate of loading and the loading condition. The rate of stress modifies the crack development and causes a slow and stable increase of micro-cracks until the unstable condition is reached during tertiary creep. This structural damage can be correlated to the evolution of micro-cracks or hits by relating the rate of the cumulated number of $\mathrm{AE}$ hits $(N)$ and the number obtained at the end of the test $\left(N_{\max }\right)$, corresponding to the total failure where the scalar damage value is equal to 1 (Carpinteri, Lacidogna, \& Pugno, 2007):

$$
D_{\mathrm{EA}}=\frac{N}{N_{\max }}
$$

where $N_{\max }=3425$ and $N_{\max }=5900$ for the beams loaded at $85 \%$ and $70 \%$, respectively. Figure 6.17 shows the evolution of the damage coefficient during flexural creep tests at $70 \%$ and $85 \%$. The rate of damage measured for the creep at $85 \%$ is more important in correlation with the rate of loading and the kinetics of creep displacement. Before the failure, creep displacement increases with an exponential function, and residual lifetime duration can then be estimated. This damage accumulation evolves as a bathtub-shaped curve and can be described using the Weibull

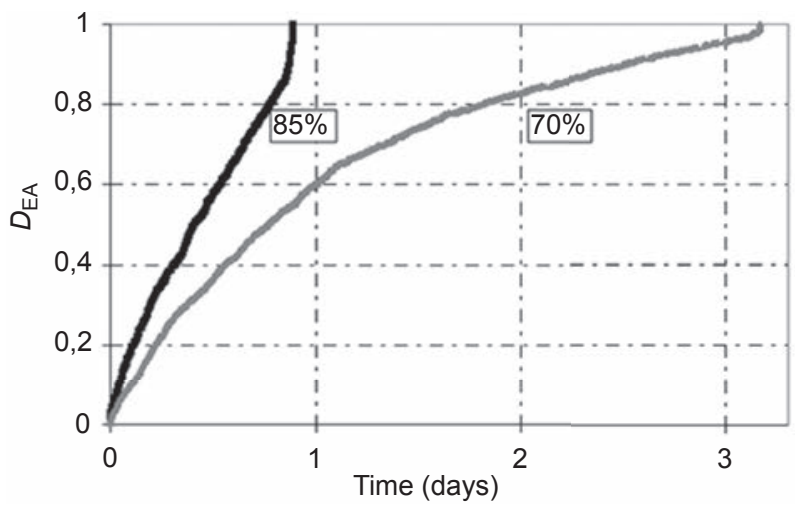

Figure 6.17 Evolution of the damage coefficient during desiccation creep.

Source: Saliba et al. (2014). 
function (Verstrynge, Schueremans, Van Gemert, \& Wevers, 2009). This suggests a method to predict the rupture by following the AE activity during creep and allows estimating the degree of concrete deterioration at an early stage of the deformation before the macro-crack formation.

\subsection{Conclusions}

$\mathrm{AE}$ analysis yields a wealth of information about the fracture process and helps in the understanding of micro-cracking and its role in mechanical behavior. The AE technique could be used to observe localization phenomena in concrete specimens. The evolution of the FPZ is clearly observed from the AE source location maps. The characteristics of the $\mathrm{AE}$ waves show a good correlation with the tension-softening properties. The decrease of the amplitude distribution after the peak load and the decrease of the width of the FPZ zone indicate a more fragile behavior for creep specimens.

Quantitative analysis of the AE data and characteristics of individual micro-cracks can be associated with two clusters for basic creep and three clusters for desiccation creep. The state of damage increases with the rate of loading, and the AE method gives sufficient data to predict the nonlinear creep and the failure of concrete.

The possibility of combining the multivariable data clustering with the moment tensor is an interesting research topic to study in the future. In addition, the simulation of AE activities at a micro- or a meso-level can be a helpful numerical tool to explain and to clarify the associated failure mechanisms.

\section{References}

Aggelis, D. G. (2011). Classification of cracking mode in concrete by acoustic emission parameters. Mechanics Research Communications, 38(3), 153-157. http://dx.doi.org/ 10.1016/j.mechrescom.2011.03.007.

Alam, S. Y., Loukili, A., \& Grondin, F. (2012). Monitoring size effect on crack opening in concrete by digital image correlation. European Journal of Environmental and Civil Engineering, 16(7), 818-836.

Altoubat, S. A., \& Lange, D. A. (2001). Creep, shrinkage and cracking of restrained concrete at early age. ACI Materials Journal, 98(4), 323-331.

Atrushi., D.S., (2003). Tensile and compressive creep of early age concrete: testing and Modelling Science and Technology (Ph.D. thesis). Norway: The Norwegian University of Science and Technology Trondheim.

Barpi, F., \& Valente, S. (2005). Lifetime evaluation of concrete structures under sustained postpeak loading. Engineering Fracture Mechanics, 72(16), 2427-2443. http://dx.doi.org/ 10.1016/j.engfracmech.2005.03.010.

Bazant, Z. P., \& Gettu, R. (1992). Rate effect and load relaxation in static fracture of concrete. ACI Materials Journal, 89(5), 456-468.

Bazant, Z. P., \& Li, Y. (1997). Cohesive crack with rate-dependent opening and viscoelasticity: I. mathematical model and scaling. International Journal of Fracture, 86, 247-265. 
Bazant, Z. P., \& Prasannan, S. (1989). Solidification theory for concrete creep. I: formulation. Journal of Engineering Mechanics, 115(8), 1691-1703.

Bernal, J. D., \& Megaw, H. D. (1935). The function of hydrogen in intermolecular forces. Proceeding of the Royal Society, A151, 384.

Bisschop, J., \& Van Mier, J. G. M. (2002). How to study drying shrinkage microcracking in cement-based materials using optical and scanning electron microscopy? Cement and Concrete Research, 32(2), 279-287.

Bissonnette, B., \& Pigeon, M. (2000). Le comportement viscoélastique du béton en traction et la compatibilité déformationnelle des réparations. Materials and Structures, 33, 108-118.

Bissonnette, Pigeon, M., \& Vaysburd, A. M. (2007). Tensile creep of concrete: study of its sensitivity to basic parameters. ACI Materials Journal, 104(4), 360-368.

Carpinteri, A., Lacidogna, G., \& Pugno, N. (2007). Structural damage diagnosis and life-time assessment by acoustic emission monitoring. Engineering Fracture Mechanics, 74(1-2), 273-289. http://dx.doi.org/10.1016/j.engfracmech.2006.01.036.

Carpinteri, A., Valente, S., Zhou, F., Ferrara, G., \& Melchiorri, G. (1997). Tensile and flexural creep rupture tests on partially-damaged concrete specimens. Materials and Structures, 30(5), 269-276.

Carrasquillo, R. L., Slate, F. O., \& Nilson, A. H. (1981). Microcracking and behavior of high strength concrete subjected to short-term loading. ACI Journal, 78(3), 179-186.

Chen, B., \& Liu, J. (2004). Effect of aggregate on the fracture behavior of high strength concrete. Construction and Building Materials, 18(8), 585-590. http://dx.doi.org/10.1016/ j.conbuildmat.2004.04.013.

Chotard, T., Quet, A., Ersen, A., \& Smith, A. (2006). Application of the acoustic emission technique to characterise liquid transfer in a porous ceramic during drying. Journal of the European Ceramic Society, 26(7), 1075-1084. http://dx.doi.org/10.1016/j.jeurceramsoc.2005.01.048.

Chotard, T., Smith, A., \& Quet, A. (2007). Characterisation of liquid transfer processes and water adsorption mechanism on a porous ceramic by acoustic emission means. Journal of the European Ceramic Society, 27(2-3), 457-462. http://dx.doi.org/10.1016/ j.jeurceramsoc.2006.04.171.

Cook, B. D. J. (1972). Some aspects of the mechanism of tensile creep. ACI Journal, 69, 645-649.

Cook, D. J., \& Haque, M. N. (1974). The tensile creep and fracture of desiccated concrete and mortar on water sorption. Materials and Structures, 7(3), 191-196.

Denarié, E., Cécot, C., \& Huet, C. (2006). Characterization of creep and crack growth interactions in the fracture behavior of concrete. Cement and Concrete Research, 36(3), 571-575. http://dx.doi.org/10.1016/j.cemconres.2005.11.011.

Finck, F., Yamanouchi, M., Reinhardt, H., \& Grosse, C. U. (2003). Evaluation of mode I failure of concrete in a splitting test using acoustic emission technique. International Journal of Fracture, 124, 139-152.

Freudenthalt, A. M., \& Roll, F. (1958). Creep and creep recovery of concrete under high compressive stress. Journal of the American Concrete Institute, 29(12), 1111-1142.

Garas. V.Y. (2009). Multi-scale investigation of tensile creep of ultra-high performance concrete for bridge applications (Ph.D. thesis). School of Civil and Environmental Engineering, Georgia Institute of Technology.

Ghosh, R. S. (1973). A hypothesis on mechanism of maturing creep of concrete. Matériaux et Constructions, 6(31), 23-27.

Glanville, W. H., \& Thomas, F. G. (1939). Further investigation on the creep or flow of concrete under load. In Building Research Technical Paper, Department of Scientific and Industrial Research 21. 
Granger, S., Loukili, A., Pijaudier-Cabot, G., \& Chanvillard, G. (2007). Experimental characterization of the self-healing of cracks in an ultra high performance cementitious material: mechanical tests and acoustic emission analysis. Cement and Concrete Research, 37(4), 519-527. http://dx.doi.org/10.1016/j.cemconres.2006.12.005.

Grosse, C. U., \& Finck, F. (2006). Quantitative evaluation of fracture processes in concrete using signal-based acoustic emission techniques. Cement and Concrete Composites, 28(4), 330-336. http://dx.doi.org/10.1016/j.cemconcomp.2006.02.006.

Hadjab, H. S., Thimus, J., \& Chabaat, M. (2007). The use of acoustic emission to investigate fracture process zone in notched concrete beams. Current Science, 93(5), 648-653.

Haidar, K., Pijaudier-Cabot, G., Dubé, J. F., \& Loukili, A. (2005). Correlations between the internal length, the fracture process zone and size effect in mortar and model materials. Materials and Structures, 38, 201-210. http://dx.doi.org/10.1617/14053.

Hansen, E. A. (1991). Influence of sustained load on the fracture energy and the fracture zone of concrete. In J. G. M. van Mier, \& A. Bakker (Eds.), Rock and ceramics (pp. 829-838). UK: E\&FN Spon.

Hillerborg, A. (1985). The theoretical basis of a method to determine the fracture energy $G f$ of concrete. Materials and Structures, 18(106), 291-296.

Idiart, A. E., López, C. M., \& Carol, I. (2011). Chemo-mechanical analysis of concrete cracking and degradation due to external sulfate attack: a meso-scale model. Cement and Concrete Composites, 33(3), 411-423. http://dx.doi.org/10.1016/j.cemconcomp.2010.12.001.

Kim, B., \& Weiss, W. J. (2003). Using acoustic emission to quantify damage in restrained fiberreinforced cement mortars. Cement and Concrete Research, 33(2), 207-214.

Kostopoulos, V., Loutas, T., Kontsos, A., Sotiriadis, G., \& Pappas, Y. (2003). On the identification of the failure mechanisms in oxide/oxide composites using acoustic emission. NDT \& E International, 36(8), 571-580. http://dx.doi.org/10.1016/S0963-8695(03) 00068-9.

Landis, E. N. (1999). Micro-macro fracture relationships and acoustic emissions in concrete. Construction and Building Materials, 13, 65-72.

Landis, E. N., \& Baillon, L. (2002). Experiments to relate acoustic emission energy to fracture energy of concrete. Journal Engineering Mechanics, 128(6), 698-702.

Landis, E. N., \& Shah, S. P. (1995). The influence of microcracking on the mechanical behavior of cement based materials. Cement Based Materials, 2, 105-118.

Li, Z. J., \& Shah, S. P. (1994). Localization of microcracking in concrete under uniaxial tension. ACI Materials Jounal, 91(4), 372-381. http://dx.doi.org/10.14359/4052.

Liniers, A. D. (1987). Microcracking of concrete under compression and its influence on tensile strength. Materials and Structures, 20(2), 111-116. http://dx.doi.org/10.1007/ BF02472746.

Lura, P., Couch, J., Jensen, O. M., \& Weiss, J. (2009). Early-age acoustic emission measurements in hydrating cement paste: evidence for cavitation during solidification due to selfdesiccation. Cement and Concrete Research, 39(10), 861-867. http://dx.doi.org/10.1016/ j.cemconres.2009.06.015.

Masuero, J. R. (1995). Crack growth initiation in concrete like materials in the presence of creep. In SMiRT Conference, Stuttgart, 156(1-2), pp. 209-218.

Mazzotti, C., \& Savoia, M. (2002). Nonlinear creep, Poisson's ratio, and creep-damage interaction of concrete in compression. ACI Materials Journal, 99(5), 450-457.

Meyers, B. L., Slate, F. O., \& Winter, G. (1969). Relationship between time-dependent deformation and microcracking of plain concrete. ACI Materials Journal, 66(1), 60-68.

Ngab, A. S., Slate, F. O., \& Nilson, A. H. (1981). Microcracking and time-dependent strains in high strength concrete. ACI Materials Journal, 11, 262-268. 
Ohtsu, M., Kaminaga, Y., \& Munwam, M. C. (1999). Experimental and numerical crack analysis of mixed-mode failure in concrete by acoustic emission and boundary element method. Construction and Building Materials, 13, 57-64.

Oja, E. (1989). Neural networks, principal components, and subspaces. International Journal of Neural Systems, 1, 61-68.

Omar, M., Loukili, A., Pijaudier-cabot, G., \& Le Pape, Y. (2009). Creep-damage coupled effects: experimental investigation on bending beams with various sizes. Journal of Materials in Civil Engineering, 21(2), 65-72.

Otsuka, K., \& Date, H. (2000). Fracture process zone in concrete tension specimen. Engineering Fracture Mechanics, 65(2-3), 111-131.

Rao, G. A., \& Prasad, B. K. R. (2002). Fracture energy and softening behavior of high-strength concrete. Cement and Concrete Research, 32, 247-252.

RILEM 50-FMC Recommendation. (1985). Determination of fracture energy of mortar and concrete by means of three-point bend test on notched beams. Materials and Structures, 18 , 285-290.

RILEM TC212-ACD. (2010). Recommendation of RILEM TC 212-ACD : acoustic emission and related NDE techniques for crack detection and damage evaluation in concrete. Materials and Structures, 43, 1187-1189. http://dx.doi.org/10.1617/s11527-010-9638-0.

Rossi, P., Godart, N., Robert, J. L., Gervais, J. P., \& Bruhat, D. (1994). Investigation of the basic creep of concrete by acoustic emission. Materials and Structures, 27, 510-514.

Rossi, P., Robert, J. L., Gervais, J. P., \& Bruhat, D. (1989). Identification of the physical mechanisms underlying acoustic emissions during the cracking of concrete. Materials and Structures, 22, 194-198.

Rossi, P., Robert, J. L., Gervais, J. P., \& Bruhat, D. (1990). The use of acoustic emission in fracture mechanics applied to concrete. Engineering Fracture Mechanics, 35, 751-763.

Rossi, P., Tailhan, J.-L., Le Maou, F., Gaillet, L., \& Martin, E. (2012). Basic creep behavior of concretes investigation of the physical mechanisms by using acoustic emission. Cement and Concrete Research, 42(1), 61-73. http://dx.doi.org/10.1016/j.cemconres.2011.07.011.

Saliba, J., Grondin, F., Matallah, M., Loukili, A., \& Boussa, H. (2012). Relevance of a mesoscopic modeling for the coupling between creep and damage in concrete. Mechanics of Time-Dependent Materials, 17(3), 481-499. http://dx.doi.org/10.1007/s11043-012-9199-4.

Saliba, J., Loukili, A., Grondin, F., \& Regoin, J.-P. (2012). Experimental study of creep-damage coupling in concrete by acoustic emission technique. Materials and Structures, 45(9), 1389-1401. http://dx.doi.org/10.1617/s11527-012-9840-3.

Saliba, J., Loukili, A., Grondin, F., \& Regoin, J.-P. (2014). Identification of damage mechanisms in concrete under high level creep by the acoustic emission technique. Materials and Structures, 47(6), 1041-1053. http://dx.doi.org/10.1617/s11527-013-0113-6.

Shah, S. P., \& Chandra, S. (1970). Fracture of concrete subjected to cyclic and sustained loading. ACI Materials Journal, 67(10), 816-827.

Shah, S. P., \& Choi, S. (1999). Nondestructive techniques for studying fracture processes in concrete. International Journal of Fracture, 98, 351-359.

Shah, S. P., \& Ouyang, C. (1994). Fracture mechanics for failure of concrete. Annual Review of Materials Science, 24, 293-320.

Van Mier, J. G. M. (2008). Framework for a generalized four-stage fracture model of cementbased materials. Engineering Fracture Mechanics, 75(18), 5072-5086. http://dx.doi.org/ 10.1016/j.engfracmech.2008.07.011.

Verstrynge, E., Schueremans, L., Van Gemert, D., \& Wevers, M. (2009). Monitoring and predicting masonry's creep failure with the acoustic emission technique. NDT \& $E$ International, 42(6), 518-523. http://dx.doi.org/10.1016/j.ndteint.2009.03.001. 
Wu, K., Chen, B., \& Yao, W. (2000). Study on the AE characteristics of fracture process of mortar, concrete and steel-fiber-reinforced concrete beams. Cement and Concrete Research, 30, 1495-1500.

Zhang, D., \& Wu, K. (1999). Fracture process zone of notched three-point-bending concrete beams. Cement and Concrete Research, 29, 1887-1892.

Zhou, F.P., Barn, B.I.G., Lydon, F.D., College, W., \& Iyf, C.F. (1995). Fracture properties of high strength concrete with varying silica fume content and aggregates. School of Engineering, Division of Civil Engineering, 25(3), 543-552. 